\section{Response of Six Dwarf-type Bermudagrasses to Trinexapac-ethyl}

\author{
Patrick E. McCullough ${ }^{1}$ \\ Department of Plant Biology and Pathology, Rutgers, The State University of \\ New Jersey, New Brunswick, NJ 08901-8520 \\ Haibo Liu² and Lambert B. McCarty
Department of Horticulture, Clemson University, Clemson, SC 29634-0375.
}

Additional index words. plant growth regulator (PGR), trinexapac-ethyl (TE), dwarf bermudagrass

\begin{abstract}
Trinexapac-ethyl (TE) is an effective plant growth retardant for hybrid bermudagrass; however, growth responses of various dwarf-type bermudagrass cultivars to $\mathrm{TE}$ have not been reported. Two 60-day greenhouse experiments were conducted at the Clemson Greenhouse Research Complex, Clemson, S.C., to evaluate the response of 'Champion', 'FloraDwarf', 'MiniVerde', 'MS Supreme', 'Tifdwarf', and 'TifEagle' bermudagrass with and without TE at $0.0125 \mathrm{~kg} \cdot \mathrm{ha}^{-1}$ a.i. per 10 days. From 20 to 60 days after initial treatments, TE enhanced visual quality $9 \%$ to $13 \%$ for all cultivars. From four samples, TE reduced clippings $63 \%, 63 \%, 69 \%, 62 \%, 64 \%$, and $46 \%$ for 'Champion', 'FloraDwarf', 'MiniVerde', 'Tifdwarf', and 'TifEagle', respectively. Trinexapac-ethyl enhanced root mass $\mathbf{2 3 \%}$ and $27 \%$ for 'MiniVerde' and 'FloraDwarf' bermudagrass, respectively. 'Champion', 'MS Supreme', 'Tifdwarf', and 'TifEagle' bermudagrass treated with TE had similar root mass to the untreated respective cultivars. Among untreated cultivars, 'FloraDwarf', 'MiniVerde', 'MS Supreme', and 'Tifdwarf' had similar root masses; however compared to these cultivars, 'Champion' and 'TifEagle' had $33 \%$ and $81 \%$ less root mass, respectively. Root length was unaffected by TE; however, 'Champion' and 'TifEagle' averaged $20 \%$ and $36 \%$ less root length compared to 'Tifdwarf' bermudagrass, respectively, while 'FloraDwarf', 'MiniVerde', and 'MS Supreme' had similar root length to 'Tifdwarf'. Trinexapac-ethyl safely enhanced turf quality and reduced clipping yield at $0.0125 \mathrm{~kg} \cdot \mathrm{ha}^{-1}$ per 10 days without inhibiting root growth of six dwarf-type bermudagrasses. Chemical name used: [4-(cyclopropyl-[ $\alpha]$-hydroxymethylene)-3,5-dioxo-cyclohexane carboxylic acid ethyl ester] (trinexapac-ethyl).
\end{abstract}

Bermudagrass (Cynodon spp. L.C. Rich) is the most widely used turfgrass in the southern United States for golf courses, athletic fields, parks, roadsides, and private grounds (Emmons, 2000). For golf courses, hybrid bermudagrass (Cynodon dactylon Pers. $\times$ C. transvaalensis Burtt-Davy) is the warm-season turfgrass used most commonly on putting greens in the warm-humid climatic regions (Beard, 2002). Bermudagrass putting greens have excellent wear, drought, and salt tolerances but necessitate high nitrogen fertility, full sunlight, and routine cultivation (McCarty and Miller, 2002). Bermudagrass greens have traditionally been considered inferior to creeping bentgrass (Agrostis palustris Huds.) from inabilities of cultivars, such as 'Tifdwarf', to tolerate regular mowing heights below $4.8 \mathrm{~mm}$.

Dwarf bermudagrass cultivars have recently been introduced that tolerate long-term mowing heights of $3.2 \mathrm{~mm}$ or closer (McCarty and Miller, 2002). Compared to traditional bermudagrass putting green cultivars, these grasses have finer leaf textures, higher per area shoot densities, and low growth habits suitable for close mowing and producing ball roll distances once exclusive to creeping

Received for publication 15 June 2004. Accepted for publication 2 Sept. 2004.

${ }^{1}$ Program associate.

2Professor; e-mail haibol@clemson.edu.

${ }^{3}$ Associate professor.
Inhibiting leaf growth with TE enhances color, promotes root growth, and improves ball roll distances of a dwarf-type bermudagrass cultivar, 'TifEagle' (McCullough, 2004). Furthermore, when dwarf bermudagrass leaf growth is inhibited by TE, plant nutrients may be reallocated away from shoots to roots, thus improving nutrient use efficiency (McCullough, 2004). Bunnell (2003) found suppressing 'TifEagle' bermudagrass growth with TE increases chlorophyll per unit leaf area which helped maintain commercially acceptable turf under low light intensities. Higher nonstructural carbohydrates were also noted, which may be advantageous for promoting root growth.

An application method commonly implemented in dwarf bermudagrass maintenance is applying TE at 0.008 (a.i.) $\mathrm{kg} \cdot \mathrm{ha}^{-1} \cdot$ week $^{-1}$ (Lowe, personal communication). Using low rates and incremental applications is a safer regimen to reduce bermudagrass injury by allowing growth adjustments to the introduced compound. Furthermore, applying TE at low rates and frequent intervals may coincide with routine fertilizations and fungicide applications. From the success of applying TE to 'TifEagle' bermudagrass, it is reasonable to consider that other dwarf-type bermudagrasses would benefit from its use. However, research is lacking to verify this. The objective of this experiment was to investigate growth responses of six dwarf-type bermudagrasses with and without TE applications.

\section{Materials and Methods}

Two studies were conducted at the Clemson University Greenhouse Research Complex, Clemson, S.C., from January to March 2004 (Study 1) and April to June 2004 (Study 2). Greenhouse day/night temperatures were set for about $26 / 20^{\circ} \mathrm{C}$. Due to reduced lighting during winter months, supplemental lighting was added for about $3 \mathrm{~h} \cdot \mathrm{d}^{-1}$ at $50 \mu \mathrm{mol} \cdot \mathrm{m}^{-2} \cdot \mathrm{s}^{-1}$. The experimental design was a randomized complete block with four replications of twelve polyvinylchloride containers per block. To help reduce light variability, blocks were rotated biweekly and experimental units rerandomized within. 'TifEagle' and 'Champion' bermudagrass plugs were collected from experimental greens located at the Turf Service Center, Clemson, established in July 2002 and 2003, respectively. 'Tifdwarf' and 'MiniVerde' bermudagrass sod was obtained from American Turf in Duluth, Ga. 'FloraDwarf' bermudagrass sod was obtained from the University of Florida, Gainesville. 'MS Supreme' bermudagrass sod was provided by Mississippi State University, Mississippi State.

Sod was established in $10 \mathrm{~cm}$ pots in the greenhouse for about 4 weeks. Turf plugs were washed free of soil, roots were cut to about 2.5 $\mathrm{cm}$ from the thatch layer, and sod was then transplanted to polyvinyl chloride containers. Containers were built approximately to United States Golf Association specification (USGA Green Section Staff, 1993) to help mimic field conditions. A rootzone mix(by volume) of 85 sand : 15 peatmoss was the soil medium 
Table 1. Pooled visual quality from 20, 30, 40, 50, and $60 \mathrm{~d}$ after initial treatments for six dwarftype bermudagrasses treated with and without trinexapac-ethyl at $0.0125 \mathrm{~kg} \cdot \mathrm{ha}^{-1}$ per $10 \mathrm{~d}$ in two combined greenhouse experiments.

\begin{tabular}{lcc}
\hline & \multicolumn{2}{c}{ Visual quality } \\
\cline { 2 - 3 } Cultivar & Untreated & Treated \\
\hline Champion & 7.0 & $7.8^{* * * * *}$ \\
FloraDwarf & 7.0 & $7.6^{* * * *}$ \\
MiniVerde & 7.0 & $7.9^{* * * * *}$ \\
MS Supreme & 7.0 & $7.7^{* * * * *}$ \\
Tifdwarf & 6.8 & $7.6^{* * * * *}$ \\
TifEagle & 6.8 & $7.6^{* * * *}$ \\
Mean & 6.9 & $7.7^{* * * *}$ \\
\hline
\end{tabular}

${ }^{2}$ Visual quality was rated on a 1 to 9 scale with $1=$ dead turf and $9=$ dark green turf. Ratings below 7 were considered unacceptable.

****Significant at $P<0.0001$ by row.

Table 2. Pooled clipping yield of six dwarftype bermudagrass treated with and without trinexapac-ethyl at $0.0125 \mathrm{~kg} \cdot \mathrm{ha}^{-1}$ per $10 \mathrm{~d}$ in two combined greenhouse experiments.

\begin{tabular}{lcc}
\hline & \multicolumn{2}{c}{$\begin{array}{c}\text { Dry clipping yield } \\
\left(\mathrm{g} \cdot \mathrm{m}^{-2}\right)\end{array}$} \\
\cline { 2 - 3 } Cultivar & Untreated & Treated \\
\hline Champion & 1.50 & $0.55^{* * * * *}$ \\
FloraDwarf & 1.01 & $0.37^{* * * * *}$ \\
MiniVerde & 1.34 & $0.41^{* * * * *}$ \\
MS Supreme & 1.22 & $0.46^{* * * * *}$ \\
Tifdwarf & 1.26 & $0.45^{* * * * *}$ \\
TifEagle & 1.50 & $0.81^{* * * * *}$ \\
Mean & 1.31 & $0.51^{* * * * *}$ \\
\hline
\end{tabular}

${ }^{\mathrm{z} C l i p p i n g s ~ w e r e ~ h a r v e s t e d ~ 15, ~ 30, ~ 45, ~ a n d ~} 60 \mathrm{~d}$ after initial treatments.

**** Significant at $P<0.0001$ by row.

consisting of $6 \%$ coarse sand ( 0.5 to $1.0 \mathrm{~mm})$, $30 \%$ medium sand ( 0.25 to $0.5 \mathrm{~mm}), 48 \%$ fine sand $(0.1$ to $0.25 \mathrm{~mm})$, and $16 \%$ very fine sand $(<0.1 \mathrm{~mm})$. Containers had 40-cm depths with $177-\mathrm{cm}^{2}$ surface areas and had drainage holes cut at about $6 \mathrm{~mm}$ at the bottom. Starting fertilizer (9-18-17; N- $\mathrm{P}_{2} \mathrm{O}_{5}-\mathrm{K}_{2} \mathrm{O}$; Scott's, Marysville, Ohio) was mixed into the soil with $\mathrm{N}$ at $48 \mathrm{~kg} \cdot \mathrm{ha}^{-1}$.

After transplanting sod to containers, a three week establishment period was allowed before initial treatments. Turf was irrigated and mowed with automatic grass sheers (Black and Decker, Towson, Md.) at $4 \mathrm{~mm} 5 \mathrm{~d} \cdot$ week $^{-1}$. Ammonium nitrate solution was applied at 17 $\mathrm{kg} \cdot \mathrm{ha}^{-1} 10,20,40$, and $50 \mathrm{~d}$ after initial treatment(DAIT). Agreens grade granular fertilizer, 18-3-18 (Andersons's, Maumee, OH), was applied at $17 \mathrm{~kg} \cdot \mathrm{ha}^{-1} 30$ DAIT. Trinexapac-ethyl was applied six times at $0.0125 \mathrm{~kg} \cdot \mathrm{ha}^{-1}$ per 10 $\mathrm{d}$ with a greenhouse spray chamber (model SB6-094; Devries Manufacturing, Hollandale, Minn.) with a 6-hp pump (model 919.165110; Craftsman) delivering $720 \mathrm{~L} \cdot \mathrm{ha}^{-1}$. Bermudagrass was not cut, watered, or fertilized within $4 \mathrm{~h}$ before or after TE applications.

Turf quality was rated weekly on a 1 to 9 scale with 9 being dark green turf and 1 completely dormant turf. Ratings below 7 were considered unacceptable. Turfinjury was evaluated on a percent scale basis, where $0=$ no injury, $1 \%$ to $15 \%=$ minor discoloration, $16 \%$ to $30 \%=$ moderate injury, $>30 \%=$ unacceptable injury, and $100 \%=$ completely dead turf. Clippings were harvested every $15 \mathrm{~d}$, about $24 \mathrm{~h}$ after the last mowing. Roots were harvested from the entire container 60 DAIT and cut back to the thatch layer. Root length was determined by measuring the distance from where roots were no longer present in the soil profile to the top of the container. After harvestings, clippings and roots were ovendried at $80{ }^{\circ} \mathrm{C}$ for $48 \mathrm{~h}$, then weighed. Data were subjected to an analysis of variance with SAS General Linear Model procedure. Mean separations were based on Fishers protected LSD test at $P=0.05$.

\section{Results}

Turf injury and visual quality. Turf injury did not occur from trinexapac-ethyl (TE) applications for any bermudagrass cultivar (data not shown). Trinexapac-ethyl significantly enhanced visual quality for all cultivars on every observation from 20 to 60 DAIT; therefore, results were pooled from those dates and presented by cultivar with and without TE (Table 1). The main effect of TE enhanced bermudagrass visual quality $12 \%$ compared to the untreated. Among cultivars, TE improved visual quality $11 \%, 9 \%, 13 \%, 10 \%$, $12 \%$, and $12 \%$ for 'Champion', 'FloraDwarf', 'MiniVerde', 'MS Supreme', 'Tifdwarf', and 'TifEagle' bermudagrass, respectively.

Clipping yield. Trinexapac-ethyl significantly reduced clipping yield for all cultivars on every sampling date; therefore, clippings were pooled and presented by bermudagrass cultivar (Table 2). From four samples, TE averaged clipping yield reductions by $63 \%, 63 \%$, $69 \%, 62 \%, 64 \%$, and $46 \%$ for 'Champion', 'FloraDwarf', 'MiniVerde', 'Tifdwarf', and 'TifEagle', respectively. Comparing untreated turf, 'Champion' and 'TifEagle' bermudagrass had the most clipping yield. The untreated 'FloraDwarf', 'MiniVerde', 'MS Supreme', and 'Tifdwarf' bermudagrasses averaged $33 \%, 11 \%, 19 \%$, and $16 \%$ less clipping yield compared to 'Champion' and 'TifEagle'.

Root mass and length. Study $\times$ treatment and study $\times$ cultivar interactions did not occur; therefore, studies were combined. Root mass was enhanced $23 \%$ and $27 \%$ for 'MiniVerde' and 'FloraDwarf' bermudagrass, respectively, following TE applications (Fig. 1). 'Champion', 'MS Supreme', 'Tifdwarf', and 'TifEagle' bermudagrasses treated with TE had similar root mass to the untreated respective cultivars. Among untreated cultivars, 'FloraDwarf', 'MiniVerde', 'MS Supreme', and 'Tifdwarf' had similar root masses; however compared to these cultivars, 'Champion' and 'TifEagle' had 33\% and $81 \%$ less root mass, respectively.

All bermudagrass cultivars treated with TE had similar root length to untreated turf; however, there were highly significant differences among bermudagrass cultivars $(P$ $<0.0001)$. Root length results are presented by bermudagrass cultivar (means of treated and untreated). 'Champion' and 'TifEagle' bermudagrass averaged $20 \%$ and $36 \%$ less root length, respectively, compared to 'Tifdwarf' bermudagrass (Fig. 2). 'FloraDwarf', 'MiniVerde', and 'MS Supreme' had similar root length to 'Tifdwarf' bermudagrass.

\section{Discussion}

Applying PGRs to putting greens may enhance turf quality and provide smoother putting surfaces by inhibiting undesirable top growth (Fagerness et al., 2000; Murphy et al., 2005). Trinexapac-ethyl is considered the

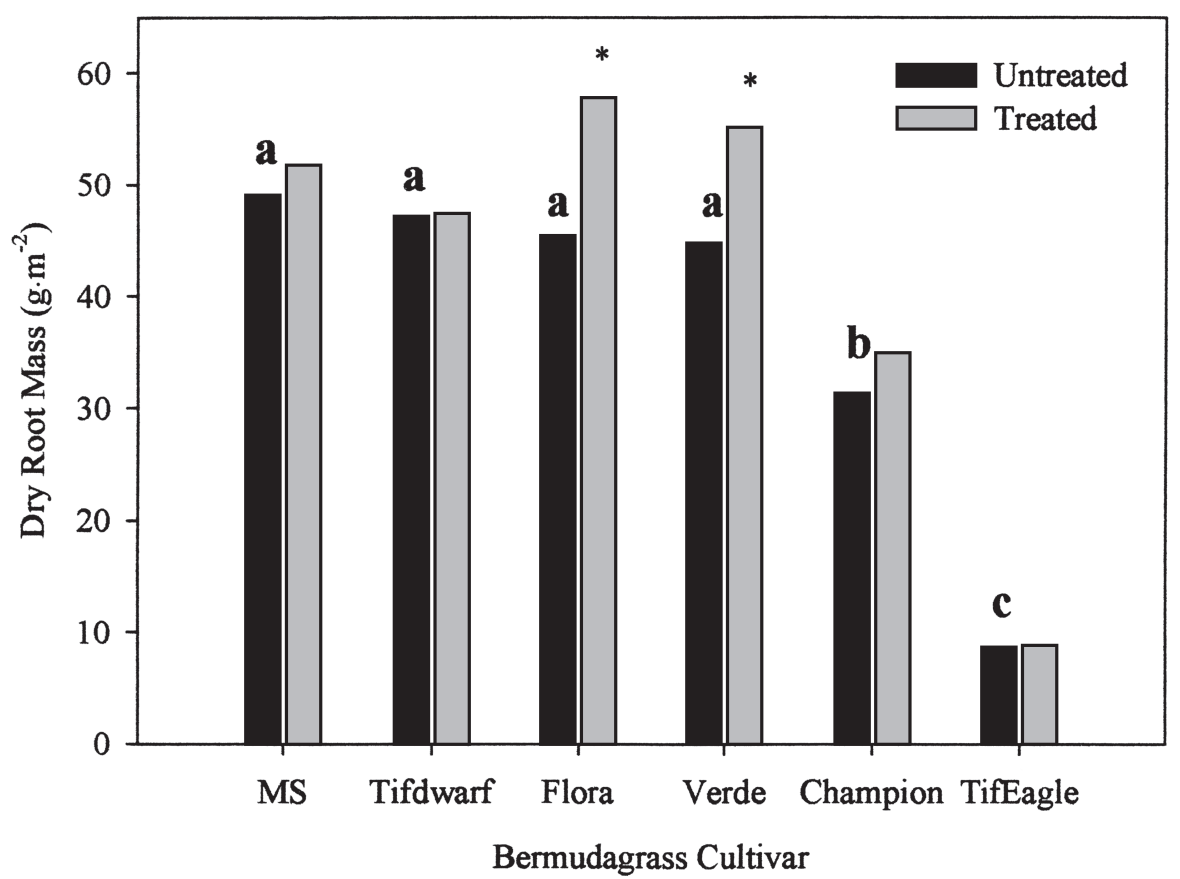

Fig. 1. Root mass after $60 \mathrm{~d}$ for six dwarf bermudagrass cultivars treated with and without trinexapac-ethyl at $0.0125 \mathrm{~kg} \cdot \mathrm{ha}^{-1}$ per $10 \mathrm{~d}$ in two combined greenhouse experiments. Different letters denote significant differences among untreatedbermudagrass cultivars at $P=0.05$ according to Fischer's protected LSD test. An asterisk (*) indicates a significant difference between a treated and untreated cultivar at $P=$ 0.05. Abbreviations: $\mathrm{MS}=$ 'MS Supreme', Flora $=$ 'FloraDwarf', Verde $=$ 'MiniVerde'. 


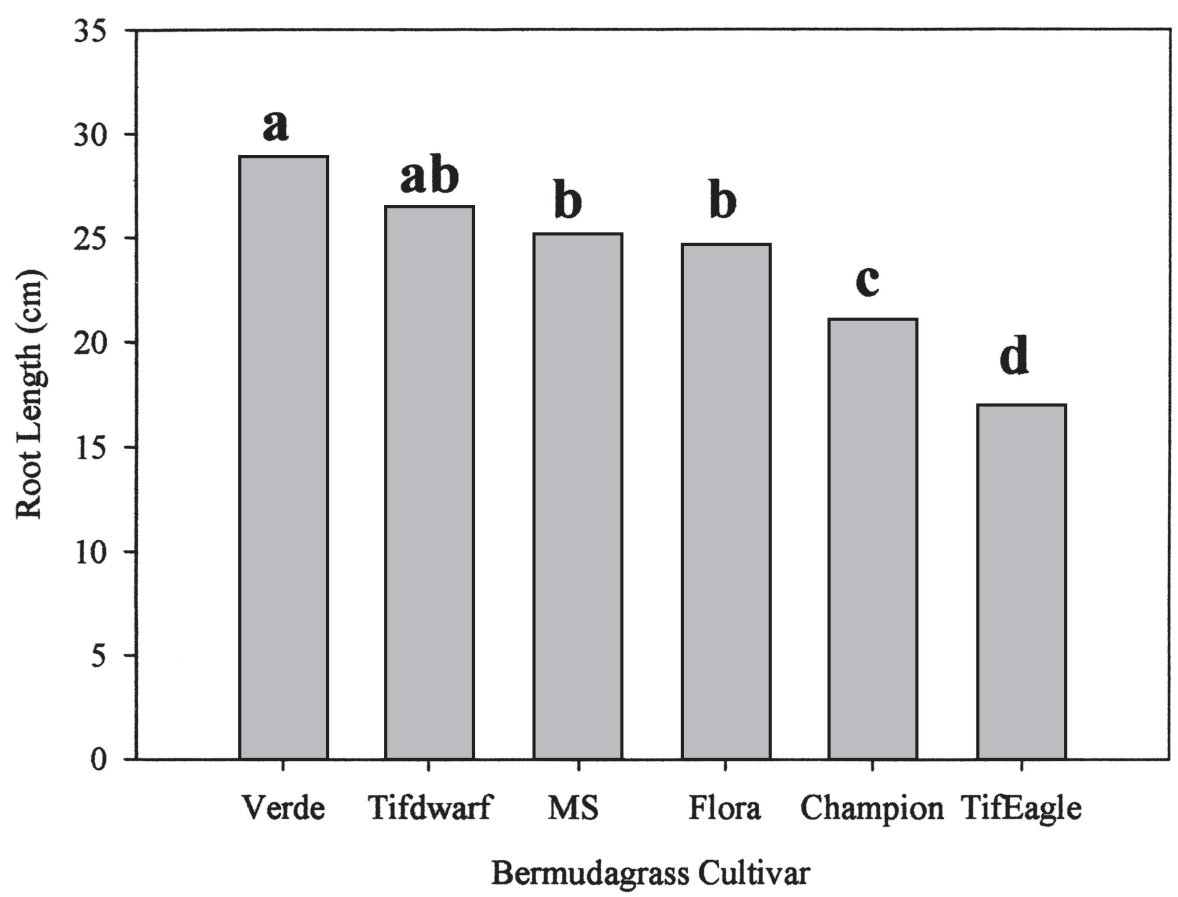

Fig. 2. Root length after $60 \mathrm{~d}$ for six dwarf bermudagrasses in two combined greenhouse experiments. Different letters indicate a significant difference at $P=0.05$ according to Fischer's protected LSD test. Abbreviations: $\mathrm{MS}=$ 'MS Supreme', Flora = 'FloraDwarf', Verde = 'MiniVerde'.

safest PGR for dwarf bermudagrasses and is the most suitable compound currently available for routine management of these grasses (McCullough et al., 2004). The application method of low TE rates at frequent intervals has been adopted by dwarf bermudagrass managers (Lowe, personal communication). Thus, evaluating growth responses of various dwarf bermudagrasses to this PGR regimen is important for the future of dwarf bermudagrass culture and research.

Trinexapac-ethyl had no deleterious effects on visual quality or root growth of six dwarf-type bermudagrasses. 'MiniVerde' and 'FloraDwarf' bermudagrass treated with TE had enhanced root mass after six applications of $0.0125 \mathrm{~kg} \cdot \mathrm{ha}^{-1}$ per $10 \mathrm{~d}$ over 2 months. Results are consistent with field studies on 'TifEagle' bermudagrass having enhanced visual color and quality resulting from increased chlorophyll concentrations following TE use (Bunnell, 2003; McCullough, 2004).
'TifEagle' bermudagrass had exceptionally lower root mass than other dwarf-type bermudagrass cultivars. With the current popularity of this cultivar, it appears that promoting root growth will be a critical cultural aspect relative to other dwarf-type bermudagrasses. Root growth comparisons among various dwarf bermudagrass cultivars are limited. White (1998) noted similar results 4 months after sprigging with 'TifEagle' bermudagrass having $63 \%$ less root mass compared to the traditional bermudagrass cultivar 'Tifdwarf'. It was observed that 'Tifdwarf', 'FloraDwarf', and 'MiniVerde' had similar total root mass after 8 weeks in this experiment, while 'Champion' and 'TifEagle' had less root mass compared to those cultivars.

As dwarf bermudagrasses continue to be planted as putting green turf, PGR use will become an important issue for long-term culture. Trinexapac-ethyl safely reduced leaf growth and enhanced visual quality without restricting root growth of six dwarf-type bermudagrasses. Overall, the TE application regime of low rates at frequent intervals appears to be effective and safe for various dwarf-type bermudagrasses.

\section{Literature Cited}

Beard, J.B. 2002. Turfmanagement for golf courses, 2nd ed. Ann Arbor Press, Chelsea, Mich.

Bunnell, B.T. 2003. Physiological response of hybrid bermudagrass (Cynodon dactylon (L.) Pers. $\times$ C. transvaalensis Burtt-Davy) to reduced light environments. $\mathrm{PhD}$ diss. Clemson Univ., Clemson, S.C.

Emmons, R.D. 2002. Turfgrass science and management. 3rd ed. Delmar Thompson Learning, Albany, N.Y.

Fagerness, M.J., F.H. Yelverton, J. Isgrigg, and R.J. Cooper. 2000. Plant growth regulators and mowing height affect ball roll and quality of creeping bentgrass putting greens. HortScience 35:755-759.

McCarty, L.B. and G.L. Miller. 2002. Managing bermudagrass turf: Selection, construction, cultural practices and pest management strategies. Sleeping Bear Press, Chelsea, Mich.

McCullough, P.E. 2004. Physiological response of 'TifEagle' bermudagrass to nitrogen and trinexapac-ethyl. MS thesis. Clemson Univ., Clemson, S.C.

McCullough, P.E., H. Liu, L.B. McCarty, and T. Whitwell. 2004. Response of 'TifEagle' bermudagrass to seven plant growth regulators. HortScience 39(7):1759-1762.

Murphy, T.R., T. Whitwell, B. McCarty, and F.H. Yelverton. 2005. Turfgrass plant growth regulators, p. 705-714. In: L.B. McCarty (ed.). Best golf course management practices. 2nd ed. Prentice-Hall, Upper Saddle River, N.J.

Rademacher, W. 2000. Growth retardants: effects on gibberellin biosynthesis and other metabolic pathways. Annu. Rev. Plant Physiol. Plant Mol. Biol. 51:501-531.

SAS Institute. 1999. The SAS system for Windows. v. 8.2. SAS Inst., Cary, N.C.

United States GolfAssociation Green Section Staff. 1993. USGA recommendations for a method of putting green construction. The 1993 Revision. USGA Green Section Record 31(2):1-3.

Watschke, T.L., M.G. Prinster, and J.M. Brenninger 1992. Plant growth regulators and turfgrass management, p. 557-588. In: D.V. Waddington, R.N. Carrow, and R.C. Shearman (eds.). Turfgrass. Amer. Soc. Agron. Monogr. 32.

White, R.H. 1998. Performance and management of new dwarf bermudagrasses, p. 12. 1998 Semi-Annu. Res. Progr. Rpt. Texas Agr. Expt. Sta. Texas A\&M Univ. 